\title{
THERMAL RISK ASSESSMENT OF VEGETABLE OIL EPOXIDATION
}

\author{
Sébastien Leveneur*1,3, Lionel Estel ${ }^{1}$, Cyril Crua $^{2}$ \\ ${ }^{1}$ LSPC-Laboratoire de Sécurité des Procédés Chimiques, INSA Rouen, BP08, Avenue de 1’Université, 76801 \\ Saint-Etienne-du-Rouvray, France; E-mail : sebastien.leveneur@insa-rouen.fr; fax: +332 32956652 \\ ${ }^{2}$ School of Computing, Engineering and Mathematics, University of Brighton, Brighton BN2 4GJ, UK \\ ${ }^{3}$ Laboratory of Industrial Chemistry and Reaction Engineering, Process Chemistry Centre, Åbo Akademi \\ University, Biskopsgatan 8, FI-20500 Åbo/Turku, Finland;
}

Keywords: Time-to-Maximum-Rate TMR $\mathrm{ad}$, MTSR, Adiabatic temperature rise, Thermal risks assessment, Green chemistry

\begin{abstract}
This article describes thermal risks assessment of vegetable oil epoxidation by peroxycarboxylic acid. It is a liquid-liquid system where several exothermic reactions occur. Acetic acid was used as the carboxylic acid, and oleic acid was chosen as a model molecule because it is a common fatty acid in the triglyceride molecule. Differential scanning calorimetry (DSC) and accelerating rate calorimetry (ARC) were used to determine safety criteria such as the final temperature $\left(\mathrm{T}_{\mathrm{Final}}\right), \mathrm{T}_{\mathrm{D} 24}$ and time-to-maximum-rate under adiabatic condition $\left(\mathrm{TMR}_{\mathrm{ad}}\right)$. We found that the calculation of $\mathrm{TMR}_{\mathrm{ad}}$ based on $\mathrm{DSC}$ data could be incorrect when assuming a zero order kinetic reaction. By using a process temperature of $70^{\circ} \mathrm{C}$, the extrapolated final temperature was found to be $544^{\circ} \mathrm{C}$ from DSC experiments, $\mathrm{T}_{\mathrm{D} 24}$ was estimated to $20^{\circ} \mathrm{C}$ based on ARC experiment and $\mathrm{TMR}_{\mathrm{ad}}$ was calculated to 164 min from ARC experiments. These criteria indicate that the process can lead to full accumulation of peroxides species. Therefore we recommend that vegetable oil epoxidation by peroxycarboxylic acid should not be performed in batch reactor, but in semi-batch mode.
\end{abstract}




\section{Introduction}

Biomass valorization to chemicals or to fuels is the future of chemical industry, i.e., biorefinery. In the 90s, green chemistry concept appeared [1] and pushed industries to design chemical processes that reduce or eliminate the use or generation of hazardous substances. For example for oxidation processes, hydrogen peroxide has replaced molecular oxygen or the use of heavy-metal oxidants [2]. Even if the use of biomass as feedstock is more sustainable than the use of petroleum-derived feedstock, one should keep in mind that several transformation steps are needed. These steps could involve high pressure and high temperature operating conditions, extreme $\mathrm{pH}$ and the use of oxidizing agents. Furthermore, many chemical processes treating biomass valorization occur in batch reactor increasing the risk of thermal accumulation. Thus, the thermal risk of these processes should be evaluated.

Vegetable oils in industry have been widely used as lubricant, monomer for polymer production or as biodiesel. From a chemical point of view, a vegetable oil is a triglyceride, which is an ester derived from glycerol and three fatty acids. One of the first steps is the transformation or functionalization of these molecules. For example, biodiesel is produced from the transesterification of vegetable oils by methanol. There are different ways of functionalizing vegetable oils: epoxidation, polyols synthesis or polymerization. For example, epoxidized soybean oil can be used as lubricant, plasticizer and hydrolysis of oxirane group is used for the production of polyurethanes. Here we address the epoxidation of vegetable oils [3-5]. Epoxidized vegetable oils can be seen as a platform molecule for the production of polymers, carbonated vegetable oils or diols. One of the greenest way to epoxidize such double bonds is the Prileschajew method [6]. It is an exothermic liquid-liquid chemical system where different reactions occur. Fig. 1 illustrates the mechanism of epoxidation. Due 
to the low solubility of hydrogen peroxide in the organic phase, an oxygen carrier is needed. It is the role of peroxycarboxylic acid to carry oxygen from aqueous to organic phase. Usually, peroxyacetic, peroxyformic and m-chloroperoxybenzoic acid are used and are produced insitu. Growing interest for direct epoxidation by using only hydrogen peroxide was investigated by different research teams [7-8]. But the heterogeneous catalysts developed for the direct epoxidation by hydrogen peroxide are less efficient than the Prileschajew method.

\section{Here Fig. 1}

Bunton et al. [9] have demonstrated that carboxylic acid perhydrolysis was a nucleophilic substitution. Moreover, Shi et al. [10] have demonstrated by quantum chemical calculation that olefin epoxidation by peroxycarboxylic acids is a nucleophilic transfer ( $\pi$-electrons of alkene) toward the peroxo bond of peroxycarboxylic acids. Thus, perhydrolysis and epoxidation are not occurring through free-radical reactions. Under normal process conditions, i.e., atmospheric pressure and temperature range of $60-70^{\circ} \mathrm{C}$, decomposition of hydrogen peroxide and peroxyacetic acid can be neglected in absence of metal impurities [11]. At higher temperature process, peroxide species decomposition can occur through freeradical reactions, which are no identified. These radicals can interfere with the classical simplified mechanism illustrated in Fig. 1.

The most produced epoxidized vegetable oil is epoxidized soybean oil, with a production of around 200000 tons in 2011 [12]. The unit process is batch or semi-batch operation with a risk of thermal accumulation. The worst-case scenario is a thermal runaway leading to a pressure increase due to the non-condensable products and vapor pressure of the liquid components. It is essential to discriminate synthesis reactions occurring at normal process temperature, and secondary reactions occurring at higher temperature. Secondary reactions 
are more temperature sensitive than synthesis reactions due to their higher activation energies and lead to the formation of non-condensable gaseous products. In the epoxidation process, synthesis reactions are carboxylic acid perhydrolysis, epoxidation and ring-opening reactions. Decomposition reactions are peroxycarboxylic acid and hydrogen peroxide decompositions. The consecutive and parallel kinetic reactions (Fig. 1) make the risk assessment rather complex, especially when synthesis and decomposition reactions can occur at same temperature range due to the presence of peroxyformic acid. Peroxyformic acid is more reactive and unstable than peroxyacetic acid [13], thus epoxidation reaction is faster and more exothermic. Due to its instability, the spontaneous decomposition of peroxyformic acid occurs at process temperature [14]. Furthermore, formic acid is a stronger carboxylic acid than acetic acid, thus favoring ring-opening reactions. For these reasons we used acetic acid in this study. Stoessel summarized the different thermal analysis methods to make a thermal safety assessment [15]. But how to interpret the safety criteria obtained by these methods for multiphase reactions system?

Several articles address the safety assessment of pure peroxide compounds for storage [1619]. In 2010, $\mathrm{Wu}$ et al., studied the decomposition of hydrogen peroxide with different solvents [20]. You et al., studied the decomposition of lauroyl peroxide with different nitric acid concentrations [21]. Chi et al., studied the effect of propanone on hydrogen peroxide stability by using different calorimetric methods [22]. 
To the best of our knowledge, few articles have investigated multiphase composite reactions system in micro-calorimetry, and fewer still have considered vegetable oils epoxidation by peroxycarboxylic acid [23-24]. The first goal of our approach was to identify the thermal risk of a chemical process through the product of its probability and severity, without requiring detailed kinetic and thermodynamic studies. Our approach was to use classical microcalorimetry devices as several environmental and safety agencies or industries do for their safety assessments. It was in that logic that thermal risk assessment of vegetable oils by peroxycarboxylic acid was performed in this article.

The goal of this article was to compare the safety criteria obtained by differential scanning calorimetry and accelerating rate calorimetry. Oleic acid was chosen as a model molecule and acetic acid was used as carboxylic acid. 
2. Experimental section

\subsection{Differential Scanning Calorimetry (DSC)}

DSC, TA Q1000 with purge using extra pure nitrogen $\left(50 \mathrm{~L} \mathrm{~min}^{-1}\right)$ was used during the experiments. Samples mass was comprised between 4-10 mg and gold-plated high pressure crucibles (M20 crucible from Swiss Institute for the Promotion of Safety \& Security) were used. Table 1 shows the experimental matrix.

\section{Here Table 1.}

\subsection{Accelerating Rate calorimeter (ARC)}

Netzsch MMC 274 Nexus $^{\circledR}$ was used during the adiabatic experiment. Sample mass was around 1 gram and was introduced into a stainless steel tube-shaped container. Initial reaction temperature and pressure were room temperature $\left(\mathrm{ca} .20^{\circ} \mathrm{C}\right.$ ) and atmospheric pressure, respectively. The mode Heat-Wait-and-Search was used with a thermal sensitivity of $0.02 \mathrm{~K}$ $\min ^{-1}$. According to the ARC manufacturer, the protocol ASTM E 1981 has been used. 


\section{Theoretical section}

The purpose of this section is to present the different safety criteria used in this manuscript and how they were derived. By considering a batch reactor operating under isothermal mode, in case of cooling failure the system can move from isothermal to adiabatic mode. Fig. 2 illustrates this shift and the safety criteria are defined.

\section{Fig. 2}

MTSR stands for Maximum Temperature of the Synthesis Reactions and corresponds to:

$\operatorname{MTSR}=T_{\mathrm{P}}+\Delta T_{\text {ad, synthesis }}$

where, $\Delta T_{\text {ad, synthesis }}$ is defined as the adiabatic temperature rise for synthesis reactions:

$$
\Delta T_{\text {ad, synthesis }}=\frac{Q_{\mathrm{r}, \text { synthesis }}}{m_{\mathrm{r}} \cdot \hat{C}_{\mathrm{P}_{\mathrm{R}}}}
$$

where $\mathrm{Q}_{\mathrm{r} \text {, synthesis }}(\mathrm{J})$ is the total amount of energy released by the reactions, $\mathrm{m}_{\mathrm{r}}(\mathrm{kg})$ is the mass of reaction mixture and $\hat{C}_{\mathrm{P}_{\mathrm{R}}}$ is the specific heat capacity of the reaction mixture in $\mathrm{J} \mathrm{kg}^{-1} \mathrm{~K}^{-1}$. 
In case of secondary reactions, final temperature $T_{\text {Final }}$ can be calculated as:

$$
T_{\text {Final }}=\mathrm{MTSR}+\Delta T_{\text {ad, decomposition }}
$$

where, $\Delta T_{\text {ad,decomposition }}$ stands for the adiabatic temperature rise for decomposition reactions:

$$
\Delta T_{\text {ad, decomposition }}=\frac{Q_{\mathrm{r}, \text { decomposition }}}{m_{\mathrm{r}}^{\prime} \cdot \hat{C}_{\mathrm{P}_{\mathrm{R}}}}
$$

In the literature, single irreversible reaction of first order is presented and the total energy released is $\mathrm{Q}_{\mathrm{r} \text {, synthesis }}=\mathrm{n}_{0} . \Delta \mathrm{H}_{\mathrm{r}}$. However, in case of composite reactions, this definition is not valid anymore. The presence of decomposition reactions is difficult to take into account because kinetic data are usually not known as well as initial conditions.

The probability criterion which is Time-to-Maximum-Rate under adiabatic conditions $\left(\mathrm{TMR}_{\mathrm{ad}}\right)$ can be difficult to estimate without kinetic data. The general consensus is to assume a zero order reaction to calculate that criterion. Then, the following equation [25] is used:

$$
\operatorname{TMR}_{\text {ad }}\left(T_{\mathrm{P}}\right)=\frac{m_{\mathrm{R}} \cdot \hat{C}_{\mathrm{PR}} \cdot R \cdot T_{\mathrm{P}}^{2}}{q_{\mathrm{P}} \cdot\left(T_{\mathrm{P}}\right) \cdot E_{\mathrm{a}}}
$$

The derivation of this equation is detailed as follows. The power released $\mathrm{q}_{\mathrm{p}}(\mathrm{W})$ by a chemical reaction is

$$
q_{\mathrm{P}}=r \cdot \Delta H_{\mathrm{r}} \cdot V
$$

where $\mathrm{r}\left(\mathrm{mol} \mathrm{L}-1 \mathrm{~s}^{-1}\right)$ is the reaction rate, $\Delta H_{\mathrm{r}}\left(\mathrm{J} \mathrm{mol}^{-1}\right)$ is the enthalpy associated to the reaction and $\mathrm{V}(\mathrm{L})$ is the reaction volume. For a zero-order reaction, $\mathrm{r}=\mathrm{k}$, where $\mathrm{k}\left(\mathrm{mol} \mathrm{L}^{-1} \mathrm{~s}^{-1}\right)$ is the kinetic rate constant. Thus, eq. (6) becomes:

$$
q_{\mathrm{P}}=k \cdot \Delta H_{\mathrm{r}} \cdot V
$$


The kinetic rate constant follows a modified Arrhenius equation such as:

$k=k_{\text {ref }} \exp \left(\frac{-E \mathrm{a}}{R}\left(\frac{1}{T}-\frac{1}{T_{\text {ref }}}\right)\right)$

where $k_{\text {ref }}=A \mathrm{e}^{-\left(\frac{E \mathrm{a}}{R T_{\text {ref }}}\right)}$, with $\mathrm{T}_{\text {ref }}$ being a reference temperature.

Thus, eq. (7) becomes:

$$
\begin{aligned}
q_{\mathrm{p}} & =k_{\text {ref }} \exp \left(\frac{-E \mathrm{a}}{R}\left(\frac{1}{T}-\frac{1}{T_{\text {ref }}}\right)\right) \cdot \Delta H_{\mathrm{r}} \cdot V \\
& =q_{\mathrm{p}, \text { ref }} \exp \left(\frac{-E \mathrm{a}}{R}\left(\frac{1}{T}-\frac{1}{T_{\text {ref }}}\right)\right)
\end{aligned}
$$

where, $q_{\mathrm{p}, \text { ref }}=k_{\mathrm{ref}} \cdot \Delta H_{\mathrm{r}} \cdot V$.

$q_{\mathrm{p}, \text { ref }}$ is the power at a reference temperature for a zero order reaction. Under adiabatic condition and with no phase change, the energy balance is simplified to:

$$
m_{\mathrm{r}} \cdot \hat{C}_{\mathrm{PR}} \cdot \frac{\mathrm{d} T_{\mathrm{r}}}{\mathrm{d} t}=q_{\mathrm{P}}\left(T_{\mathrm{r}}\right)
$$

where $T_{r}$ is the reaction temperature and $q_{p}\left(T_{r}\right)$ is the power released by the reaction at $T_{r}$.

By adding eqs (9) and (10), one gets:

$$
\frac{\mathrm{d} T_{\mathrm{r}}}{\mathrm{d} t}=\frac{q_{\mathrm{p}, \text { ref }}}{m_{\mathrm{r}} \cdot \hat{C}_{\mathrm{PR}}} \cdot \exp \left(\frac{-E \mathrm{a}}{R}\left(\frac{1}{T}-\frac{1}{T_{\text {ref }}}\right)\right)
$$

By integrating eq. (11) from process temperature to the Maximum Temperature of Synthesis Reactions, one gets:

$$
\left[\frac{-1}{\frac{E a}{R} \frac{1}{T^{2}}} \cdot \exp \left(\frac{E \mathrm{a}}{R}\left(\frac{1}{T}-\frac{1}{T_{\text {ref }}}\right)\right)\right]_{\mathrm{T}_{\mathrm{P}}}^{\mathrm{MTSR}}=\frac{q_{\mathrm{p}, \text { ref }}}{m_{\mathrm{r}} \cdot \hat{C}_{\mathrm{PR}}} \cdot\left(t_{\mathrm{MTSR}}-t_{\mathrm{T}_{\mathrm{p}}}\right)
$$


After some simplifications, Eq. (12) becomes

$$
t_{\mathrm{MTSR}}=\mathrm{TMR}_{\text {ad, synthesis }}=\frac{m_{\mathrm{r}} \hat{C}_{\mathrm{PR}} \cdot R \cdot T_{\mathrm{P}}^{2}}{q_{\mathrm{p}, \text { ref }} \cdot E \mathrm{a} \cdot \exp \left(\frac{-E \mathrm{a}}{R}\left(\frac{1}{T_{\text {ref }}}-\frac{1}{T_{\mathrm{P}}}\right)\right)}=\frac{m_{\mathrm{r}} \cdot \hat{C}_{\mathrm{PR}} \cdot R \cdot T_{\mathrm{P}}^{2}}{q_{\mathrm{p}}\left(T_{\mathrm{P}}\right) \cdot E \mathrm{a}}
$$

Using the same reasoning, one can calculate Time to Maximum Rate under adiabatic for decomposition reactions as:

$$
t_{\text {final }}=\mathrm{TMR}_{\text {ad, deconposition }}=\frac{m_{\mathrm{r}} \cdot \hat{C}_{\mathrm{PR}} \cdot R \cdot \mathrm{MTSR}^{2}}{q_{\mathrm{p}, \text { ref }} \cdot \operatorname{Ea} \cdot \exp \left(\frac{-E \mathrm{a}}{R}\left(\frac{1}{T_{\text {ref }}}-\frac{1}{\mathrm{MTSR}}\right)\right)}=\frac{m_{\mathrm{r}}^{\prime} \cdot \hat{C}_{\mathrm{PR}} \cdot \mathrm{R} \cdot \mathrm{MTSR}^{2}}{q_{\mathrm{p}}(\mathrm{MTSR}) \cdot E^{\prime} \mathrm{a}}
$$

One should keep in mind that eqs. (13) and (14) are correct for zero order reaction. These equations are often used in case of single reaction with complex kinetics or even in case of composite reactions. Indeed, one cannot know the intrinsic kinetics and by assuming a zero order for a safety assessment the worst case scenario is taken into account. However, aren't there any risks of overestimating the probability? A comparison between $\mathrm{TMR}_{\mathrm{ad}}$ obtained from DSC results and ARC was performed in that manuscript.

In case of composite reactions, one should determine which activation energy to use for eqs. (13) and (14). It is a typical problem in thermal safety assessment for complex reaction system. One method to calculate the activation energies for the synthesis and decomposition parts is the Kissinger Ozawa method [26]. It is based on the use of DSC under dynamic mode, and it could be possible to discriminate between both mechanisms [24].

Concentration evolution can be described by the following equations:

$$
\frac{\mathrm{d} C}{\mathrm{~d} t}=k \cdot f(C)
$$


Indeed, a reaction is function of the rate constant and reactant concentrations. Eq. (15) is equivalent to

$\frac{\mathrm{d} \alpha}{\mathrm{d} t}=k \cdot(1-\alpha)^{n}$

where, $\alpha$ represents the chemical advancement of a reaction.

By using Arrhenius law, the above equation becomes:

$\frac{\mathrm{d} \alpha}{\mathrm{d} t}=A \cdot \exp \left(\frac{-E_{\mathrm{a}}}{R \cdot T}\right)(1-\alpha)^{n}$

There is an extremum at this function at:

$\frac{\mathrm{d}}{\mathrm{d} t}\left(\frac{\mathrm{d} \alpha}{\mathrm{d} t}\right)=0$

which is equivalent to

$$
\begin{aligned}
& \frac{\mathrm{d}}{\mathrm{d} t}\left(\frac{\mathrm{d} \alpha}{\mathrm{d} t}\right)=0 \\
& \Leftrightarrow \frac{\mathrm{d}}{\mathrm{d} t}\left(\frac{\mathrm{d} \alpha}{\mathrm{d} t}\right)=(1-\alpha)^{\mathrm{n}} \cdot \frac{\mathrm{d}}{\mathrm{d} t}\left(A \cdot \exp \left(\frac{-E \mathrm{a}}{R T}\right)\right)+A \cdot \exp \left(\frac{-E \mathrm{a}}{R T}\right) \cdot \frac{\mathrm{d}(1-\alpha)^{\mathrm{n}}}{\mathrm{d} t} \\
& \Leftrightarrow \frac{\mathrm{d}}{\mathrm{d} t}\left(\frac{\mathrm{d} \alpha}{\mathrm{d} t}\right)=(1-\alpha)^{\mathrm{n}} \cdot \frac{\mathrm{d}}{\mathrm{d} T} \cdot \frac{\mathrm{d} T}{\mathrm{~d} t}\left(A \cdot \exp \left(\frac{-E \mathrm{a}}{R T}\right)\right)+A \cdot \exp \left(\frac{-E \mathrm{a}}{R T}\right) \cdot \frac{\mathrm{d}}{\mathrm{d} \alpha} \frac{\mathrm{d} \alpha(1-\alpha)^{\mathrm{n}}}{\mathrm{d} t}=0 \\
& \Leftrightarrow \frac{\mathrm{d}}{\mathrm{d} t}\left(\frac{\mathrm{d} \alpha}{\mathrm{d} t}\right)=(1-\alpha)^{\mathrm{n}} \cdot \frac{A \cdot E \mathrm{a}}{R T^{2}} \cdot \exp \left(\frac{-E \mathrm{a}}{R T}\right) \cdot \frac{\mathrm{d} T}{\mathrm{~d} t}-A \cdot \exp \left(\frac{-E \mathrm{a}}{R T}\right) \cdot n(1-\alpha)^{\mathrm{n}-1} \cdot \frac{\mathrm{d} \alpha}{\mathrm{d} t}=0
\end{aligned}
$$

when $\mathrm{T}=\mathrm{Tm}$ (temperature at the maximum heat flow); 


$$
\begin{aligned}
& (1-\alpha)^{\mathrm{n}} \cdot \frac{A \cdot E \mathrm{a}}{R T_{\mathrm{m}}^{2}} \cdot \exp \left(\frac{-E \mathrm{a}}{R T_{\mathrm{m}}}\right) \cdot \frac{\mathrm{d} T}{\mathrm{~d} t}=A \cdot \exp \left(\frac{-E \mathrm{a}}{R T_{\mathrm{m}}}\right) \cdot n \cdot(1-\alpha)^{\mathrm{n}-1} \cdot \frac{\mathrm{d} \alpha}{\mathrm{d} t} \\
& \Leftrightarrow(1-\alpha) \cdot \frac{E \mathrm{a}}{R T_{\mathrm{m}}^{2}} \cdot \frac{\mathrm{d} T}{\mathrm{~d} t}=n \cdot \frac{\mathrm{d} \alpha}{\mathrm{d} t}=n \cdot k \cdot(1-\alpha)^{\mathrm{n}} \\
& \Leftrightarrow \frac{E \mathrm{a}}{R T_{\mathrm{m}}^{2}} \cdot \frac{\mathrm{d} T}{\mathrm{~d} t}=n \cdot A \cdot \exp \left(\frac{-E \mathrm{a}}{R T_{\mathrm{m}}}\right) \cdot(1-\alpha)^{\mathrm{n}-1}
\end{aligned}
$$

By introducing the following notation $\beta=\frac{\mathrm{d} T}{\mathrm{~d} t}$, which represents the temperature ramp, then:

$$
\begin{aligned}
& \frac{\beta}{T_{\mathrm{m}}^{2}}=\frac{R \cdot A}{E \mathrm{a}} \cdot n \cdot(1-\alpha)^{\mathrm{n}-1} \cdot \exp \left(\frac{-E \mathrm{a}}{R T_{\mathrm{m}}}\right) \\
& \Leftrightarrow \ln \left(\frac{\beta}{T_{\mathrm{m}}^{2}}\right)=\ln (\text { constant })-\frac{E \mathrm{a}}{R T_{\mathrm{m}}}
\end{aligned}
$$

The Kissinger approach was used in this study.

In order to measure the $\mathrm{TMR}_{\mathrm{ad}}$, the adiabatic reactor was used. 


\section{Results and discussion}

\subsection{Results obtained by Differential Scanning Calorimeter}

In order to determine the effect of $\mathrm{H}_{2} \mathrm{O}_{2}$ on total energy released by the system, we conducted an experiment with an excess of hydrogen peroxide. Fig. 3 shows two DSC experiments performed under dynamic mode with different hydrogen peroxide concentrations (Table 2).

\section{$\underline{\text { Here Table } 2}$}

\section{Fig. 3}

When there is an excess of hydrogen peroxide (Case 2), the total energy released by the system is higher, i.e., $2091 \mathrm{~J} \mathrm{~g}^{-1}$. One can notice the presence of two different peaks in case of excess of hydrogen peroxide. As said in the introduction, the mechanism of vegetable oils epoxidation is complex and decomposition reactions can be the decomposition of hydrogen peroxide into oxygen and water and the different decomposition routes of peroxyacetic acid [27-28]. Thus, the second peak can be assumed to be the decomposition of the excess of hydrogen peroxide and decomposition of peroxyacetic acid into non-condensable gaseous products. 
The adiabatic temperature rise can be calculated from both experimental conditions,

$$
\begin{aligned}
& \Delta T_{\mathrm{ad}}=\frac{Q_{\mathrm{r}, \text { total }}}{m_{\mathrm{r}}^{\prime} \cdot \hat{C}_{\mathrm{P}_{\mathrm{R}}}}=816 \mathrm{~K} \text { for } \frac{\operatorname{mass} / \%(\mathrm{AA})}{\operatorname{mass} / \%\left(\mathrm{H}_{2} \mathrm{O}_{2}\right)}=0.5 \\
& \Delta T_{\mathrm{ad}}=\frac{Q_{\mathrm{r} \text { total }}}{m_{\mathrm{r}}^{\prime} \cdot \hat{C}_{\mathrm{P}_{\mathrm{R}}}}=474 \mathrm{~K} \text { for } \frac{\operatorname{mass} / \%(\mathrm{AA})}{\operatorname{mass} / \%\left(\mathrm{H}_{2} \mathrm{O}_{2}\right)}=2.0
\end{aligned}
$$

One can notice that in case of hydrogen peroxide excess, the severity of the accident is higher. The objective of this article was to make the safety assessment under normal condition and for that reason it was decided to take into consideration only the case 1, i.e., mass ratio of acetic acid on hydrogen peroxide equal to 0.5 . The following experiments were performed by using similar concentrations as case 1.

Different temperature ramps were used as illustrated on Fig. 4.

\section{Here Fig. 4}

We applied the Kissinger methodology and generated the correlation in Fig. 5.

\section{$\underline{\text { Here Fig. } 5}$}

The value of the activation energy is equal to $72090 \mathrm{~J} \mathrm{~mol}^{-1}$. To determine $\mathrm{TMR}_{\mathrm{ad}}$ from eq. (5) at process temperature, one should determine the power released by the chemical system $\mathrm{q}_{\mathrm{p}}$ and the activation energy. The power released can be determined by using DSC under isothermal condition (Figs. 6a and $b$ ). The maximal power released $\mathrm{q}_{\mathrm{p}, \max }$ was chosen to calculate the $\mathrm{TMR}_{\mathrm{ad}}$ at different process temperatures. 


\section{Fig. $6 a$}

\section{Fig. $6 b$}

By using eq. (9), it is possible to determine an average activation energy, i.e., covering synthesis and decomposition part. Fig. 7 illustrates the eq. (9).

\section{Here Fig. 7}

\section{Fig. 8}

Figs. 8 shows the evolution of TMR ad with the temperature process based on $\mathrm{q}_{\mathrm{p}, \max }$ TMR $\mathrm{Td}$ calculated with activation energy equal to 48590 or $72090 \mathrm{~J} \mathrm{~mol}^{-1}$ gives similar results. On Fig. 8, prevision values correspond to the value of $\mathrm{TMR}_{\mathrm{ad}}$ calculated with a $\mathrm{q}_{\mathrm{p} \text {,max }}$ belonging to temperature range $60-250^{\circ} \mathrm{C}$ and prediction values are obtained by using a $\mathrm{q}_{\mathrm{p} \text {,max }}$ which is outside of this range.

The safety criteria for this system by using DSC experiment are displayed in Table 2.

\section{$\underline{\text { Here Table } 3}$}

One can notice that the difference between both systems is small. One should observe that $\mathrm{T}_{\mathrm{D} 24}$ was determined by using the following assumptions:

-Eq. (5) based on a zero order reaction,

-by using the maximum power released $\mathrm{q}_{\mathrm{p}, \max }$

Furthermore, the obtained value of $\mathrm{T}_{\mathrm{D} 24}$ is far from the experimental temperature range, i.e., $24^{\circ} \mathrm{C}$. 
By using Eq. (5), the user should be aware that it was derived for a zero order reaction. In order to check if this assumption was correct, an adiabatic reactor was used. Fig. 9 shows the evolution of temperature and pressure with a $\varphi$-factor equal to 1.87 .

\section{Here Fig. 9}

The measured temperature should be corrected with the thermal inertia of the system as:

$T_{\mathrm{i}, \text { corr }}=T_{0}+\varphi \cdot\left(T_{\mathrm{i}}-T_{0}\right)$

where $\varphi$ is defined as:

$\varphi=\frac{m_{\mathrm{R}} \cdot \hat{C}_{\mathrm{P}_{\mathrm{R}}}+m_{\text {cellule }}{\hat{\mathrm{C}_{\mathrm{P}}}}_{\mathrm{P}_{\text {cllulue }}}}{m_{\mathrm{R}} \cdot \hat{C}_{\mathrm{P}_{\mathrm{R}}}}$

When the system is completely adiabatic then $\varphi=1$.

Fig. 10 shows the corrected value in function of the $\mathrm{TMR}_{\mathrm{ad}}$.

\section{$\underline{\text { Here Fig. } 10}$}

The final extrapolated temperature for $\varphi=1$ was $401.9^{\circ} \mathrm{C}$. It was not possible in our experiment to reach $\mathrm{T}_{\mathrm{D} 24}$, i.e., process temperature when $\mathrm{TMR}_{\mathrm{ad}}$ is 24 hours. It is compulsory to extrapolate that value by using Eq. (5) representing the worst-case scenario. Fig. 11 shows $\ln \left(\mathrm{TMR}_{\mathrm{ad}}\right)$ versus the inverse of the temperature process.

\section{Here Fig.11}


The value of the activation energy was of $36431 \mathrm{~J} \mathrm{~mol}^{-1}$, thus by extrapolation $\mathrm{T}_{\mathrm{D} 24}=19.69^{\circ} \mathrm{C}$. The value of $\mathrm{T}_{\mathrm{D} 24}$ was closer to the experimental temperature interval than the one obtained from DSC experiments.

\subsection{Comparison between DSC and ARC}

The safety criteria obtained by DSC and ARC are compared. From DSC, by using the dynamic mode, it was possible to notice the presence of secondary reactions and to calculate the total energy released by a chemical system. Furthermore, it is possible to determine the maximum power released by a chemical system by using the isothermal mode, which is essential for the heat exchanger scale-up. However, $\mathrm{TMR}_{\mathrm{ad}}$ obtained by DSC was overestimated due to the use of $\mathrm{q}_{\mathrm{p}, \max }$ in eq. (5) and the fact that $\mathrm{q}_{\mathrm{p}, \max }$ was not obtained at $20^{\circ} \mathrm{C}$ (Table 4 and Fig. 12). ARC is an excellent complementary calorimetry tool to estimate $\mathrm{TMR}_{\mathrm{ad}}$. In this system, it was not possible to measure directly that value and an extrapolation should have been done. The final temperature was lower with ARC because the hydrogen peroxide decomposition reaction was not triggered.

\section{$\underline{\text { Here Table } 4}$}

$\underline{\text { Here Fig. } 12}$ 


\section{Conclusions}

We assessed the thermal safety of oleic acid epoxidation by peroxyacetic acid using ARC, and DSC under both dynamic and isothermal modes. The reaction composition was similar to those used in industry, i.e., 25 mass $/ \%$ of acetic acid, 15 mass $/ \%$ of hydrogen peroxide and 30 mass $/ \%$ of oleic acid. In the case of hydrogen peroxide excess, the total energy released by the chemical system was higher and we observed synthesis and decomposition reactions.

We found that the TMR ad calculated from DSC data was higher than the TMRad calculated from ARC data. The widely used eq. (5) are derived based on zero order kinetic reactions and leads to an overestimate of the risk probability. Furthermore, it was calculated by using the maximum power released. In the case of ARC, by taking into account the thermal inertia of the system, the TMRad calculated can be assumed closer to the one in case of cooling failure.

In such system, the user should use DSC under dynamic mode to observe the presence of secondary reactions, DSC under isothermal mode to calculate the adiabatic temperature rise from the total energy released and ARC should be used to approach the value of $\mathrm{T}_{\mathrm{D} 24}$.

We estimated the adiabatic temperature rise to be $544^{\circ} \mathrm{C}$ from DSC data and the value of $\mathrm{T}_{\mathrm{D} 24}$ from $\mathrm{ARC}$ to be $20^{\circ} \mathrm{C}$, which is higher than the normal temperature process, i.e., 60 $70^{\circ} \mathrm{C}$. Thus we recommend operating under semi-batch mode to limit the accumulation of reactant inside the reactor. 


\section{Figures}

Fig. 1 Simplified mechanism of the of oleic acid epoxidation by peroxyacetic acid

Fig. 2 Cooling failure scenario accident

Fig. 3 DSC experiment at $4^{\circ} \mathrm{C} \cdot \mathrm{min}^{-1}$ at different ratio of acetic acid on hydrogen peroxide

Fig. 4 DSC under dynamic mode

Fig. 5 Kissinger plot for oleic acid epoxidaion by peroxyacetic acid

Fig. 6a DSC under isothermal condition for the epoxidation of oleic acid by peroxyacetic acid within temperature range of $60-120^{\circ} \mathrm{C}$

Fig. 6b DSC under isothermal condition for the epoxidation of oleic acid by peroxyacetic acid within temperature range of $130-250^{\circ} \mathrm{C}$

Fig. 7 Evolution of $\ln \left(q_{R X_{-} \text {max }}\right)$ versus $\frac{\square 1}{R} \square \frac{1}{\square T} \square \frac{1}{T_{\text {ref }}} \sqsubset$

Fig. $8 \mathrm{TMR}_{\mathrm{ad}}$ from DSC data

Fig. 9 Evolution of temperature and pressure in the ARC

Fig. 10 Evolution of $\mathrm{TMR}_{\mathrm{ad}}$ with $\varphi$-factor

Fig. $11 \ln \left(\mathrm{TMR}_{\mathrm{ad}}\right)$ versus $T_{\mathrm{P}}^{-1} / \mathrm{K}^{-1}$

Fig. 12 Evolution of $\mathrm{TMR}_{\mathrm{ad}}$ at different process temperatures 


\section{Tables}

Table 1 Experimental matrix

Table 2 Experimental conditions for DSC under dynamic mode

Table 3 Safety criteria from DSC results

Table 4 Comparison between DSC and ARC

\section{Acknowledgments}

This work was supported by the Academy of Finland and the European Regional Development Fund [INTERREG IVA grant number 4274]. The authors are particularly grateful to Jean-Pierre Hébert for his contribution to the experiment. 


\section{References}

1. Anastas PT, Warner JC. Green Chemistry: Theory and Practice. Oxford England; New York: Oxford University Press; 2000.

2. Noyori R. Pursuing practical elegance in chemical synthesis. Chem Commun. 2005;180711.

3. Meier MAR, Metzger JO, Schubert US. Plant oil renewable resources as green alternatives in polymer science. Chemical Society Reviews. 2007;36:1788.

4. Xia Y, Larock RC. Vegetable oil-based polymeric materials: synthesis, properties, and applications. Green Chem. 2010;12:1893-909.

5. Hernández N, Williams RC, Cochran EW. The battle for the « green » polymer. Different approaches for biopolymer synthesis: bioadvantaged vs. bioreplacement. Org Biomol Chem. $2014 ; 12: 2834-49$

6. Köckritz A, Martin A. Oxidation of unsaturated fatty acid derivatives and vegetable oils. Eur J Lipid Sci Technol. 2008;110:812-24.

7. Di Serio M, Turco R, Pernice P, Aronne A, Sannino F, Santacesaria E. Valuation of $\mathrm{Nb}_{2} \mathrm{O}_{5}-\mathrm{SiO}_{2}$ catalysts in soybean oil epoxidation. Catalysis Today. 2012;192:112-6.

8. Arends IWCE, Sheldon RA. Recent developments in selective catalytic epoxidations with $\mathrm{H}_{2} \mathrm{O}_{2}$. Topics in Catalysis. 2002;19:133-41.

9. Bunton CA, Lewis TA, Llewelyn DL. Tracer studies in the formation and reactions of organic per-acids. J Am Chem Soc. 1956;78(6):1226-1230. 
10. Shi $\mathrm{H}$, Zhang Z, Wang $\mathrm{Y}$. Mechanism on epoxidation of alkenes by peracids: A protonation-promoted pathway and its quantum chemical elucidation. J Mol Catal A: Chemical. 2005;238:13-25.

11. Sinadinović-Fišer S, Janković M, Borota O. Epoxidation of castor oil with peracetic acid formed in situ in the presence of an ion exchange resin. Chem Eng Proc. 2012;62:106-113.

12. Turco T. Industrial catalytic processes intensification through the use of microreactors. PhD dissertation, The University of Naples Federico II, Naples, 2010.

13. Leveneur S, Wärnå J, Salmi T, Murzin DY. A review: Catalytic synthesis and decomposition of peroxycarboxylic acids. Trends in chemical engineering. 2010;13:17-52.

14. Leveneur S, Thönes M, Hébert J-P, Taouk B. Salmi. From kinetic study to thermal safety assessment: application to peroxyformic acid synthesis. Ind Eng Chem Res. 2012;51:13999:14007.

15. Stoessel F. Thermal safety of chemical processes. Wiley-VCH Verlag GmbH \& Co. $\mathrm{KGaA} ; 2008$.

16. Sun D-X, Miao X, Xie C-X, Gu J, Li R. Study on thermal properties and kinetics of benzoyl peroxide by ARC and C80 methods. J Therm Anal Calorim. 2012;107:943-8.

17. Wu S-H, Chou H-C, Pan R-N, Huang Y-H, Horng J-J, Chi J-H, Shu C-M. Thermal hazard analyses of organic peroxides and inorganic peroxides by calorimetric approaches. $\mathrm{J}$ Therm Anal Calorim. 2012;109:355-64.

18. Cheng S-Y, Tseng J-M, Lin S-Y, Gupta JP, Shu C-M. Runaway reaction on tert-butyl peroxybenzoate by DSC tests. J Therm Anal Calorim. 2008;93:121-6. 
19. Casson V, Maschio G. Screening Analysis for Hazard Assessment of Peroxides Decomposition. Ind Eng Chem Res. 2012;51:7526-35.

20. Wu S-H, Chi J-H, Huang C-C, Lin N-K, Peng J-J, Shu C-M. Thermal hazard analyses and incompatible reaction evaluation of hydrogen peroxide by DSC. J Therm Anal Calorim. $2010 ; 102: 563-8$

21. You M-L, Tseng J-M, Liu M-Y, Shu C-M. Runaway reaction of lauroyl peroxide with nitric acid by DSC. J Therm Anal Calorim. 2010;102:535-9.

22. Chi J-H, Wu S-H, Charpentier J-C, I Y-P, Shu C-M. Thermal hazard accident investigation of hydrogen peroxide mixing with propanone employing calorimetric approaches. J Loss Prev Process Ind. 2012;25:142-7.

23. Salzano E, Agreda, Agreda AG, Russo V, Di Serio M, Santacesaria E. Safety criteria for the epoxydation of soybean oil in fed- batch reactor. Chemical Engineering Transactions. 2012; doi:10.3303/CET1226007

24. Leveneur S, Delannoy F, Levesqueau Y, Hebert J-P, Estel L, Taouk B, Salmi T. The limit of DSC as a Preliminary Tool to Determine the Safety Parameters? Chemical Engineering Transactions. 2014; doi:10.3303/CET1436024

25. Keller A, Stark D, Fierz H, Heinzle E, Hungerbühler K. Estimation of the time to maximum rate using dynamic DSC experiments. J Loss Prev Process Ind. 1997;10:31-41.

26. Blaine RL, Kissinger HE. Homer Kissinger and the Kissinger equation. Thermochim Acta. 2012;540:1-6. 
27. Musakka N, Salmi T, Wärnå J, Ahlkvist J, Piironen M. Modelling of organic liquid-phase decomposition reactions through gas-phase product analysis: Model systems and peracetic acid. Chem Eng Sci. 2006;61:6918-28.

28. Leveneur S, Salmi T, Musakka N, Wärnå J. Kinetic study of decomposition of peroxypropionic acid in liquid phase through direct analysis of decomposition products in gas phase. Chem Eng Sci. 2007;62:5007-5012. 


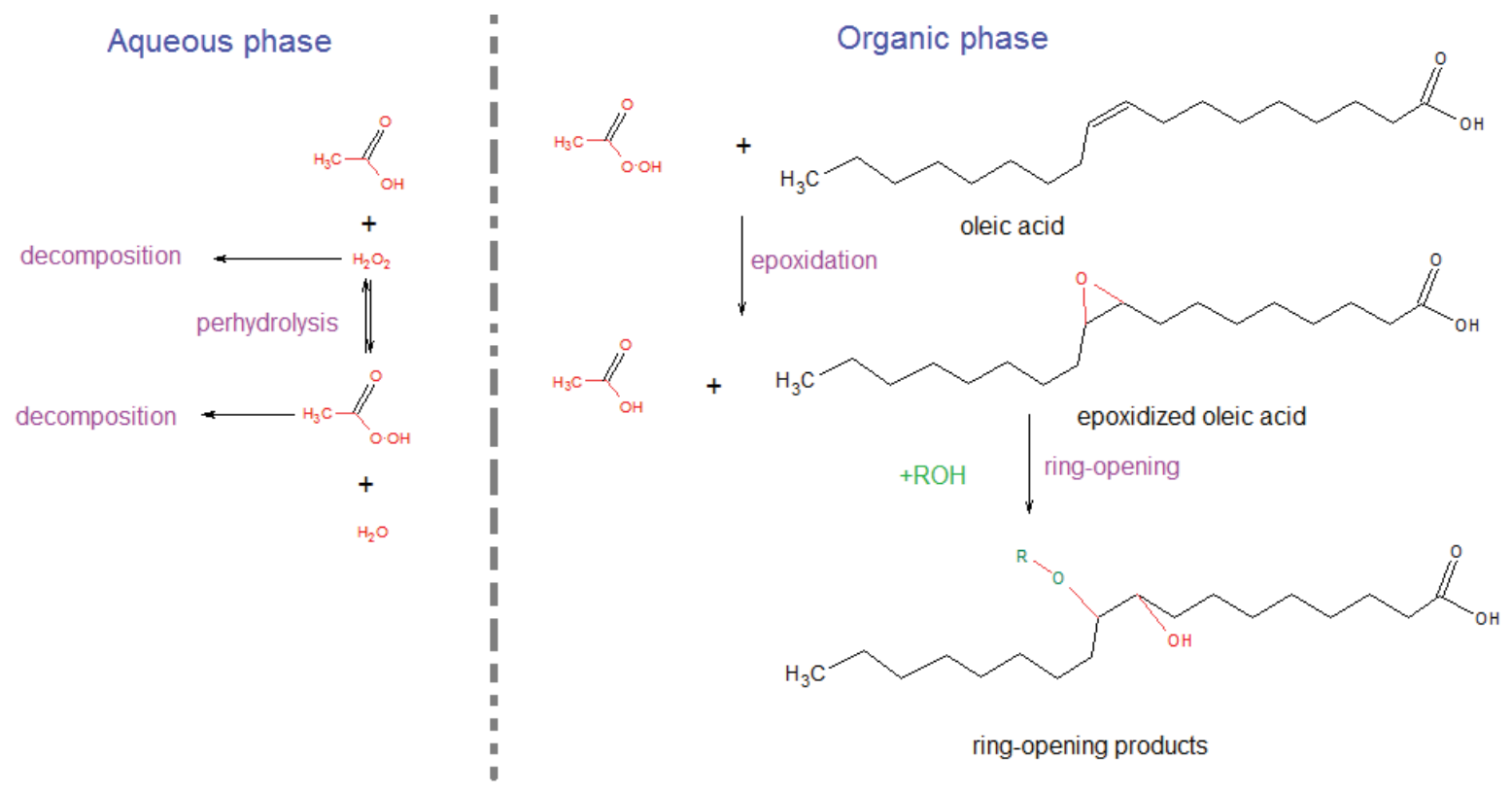

Fig. 1 Simplified mechanism of the of oleic acid epoxidation by peroxyacetic acid 


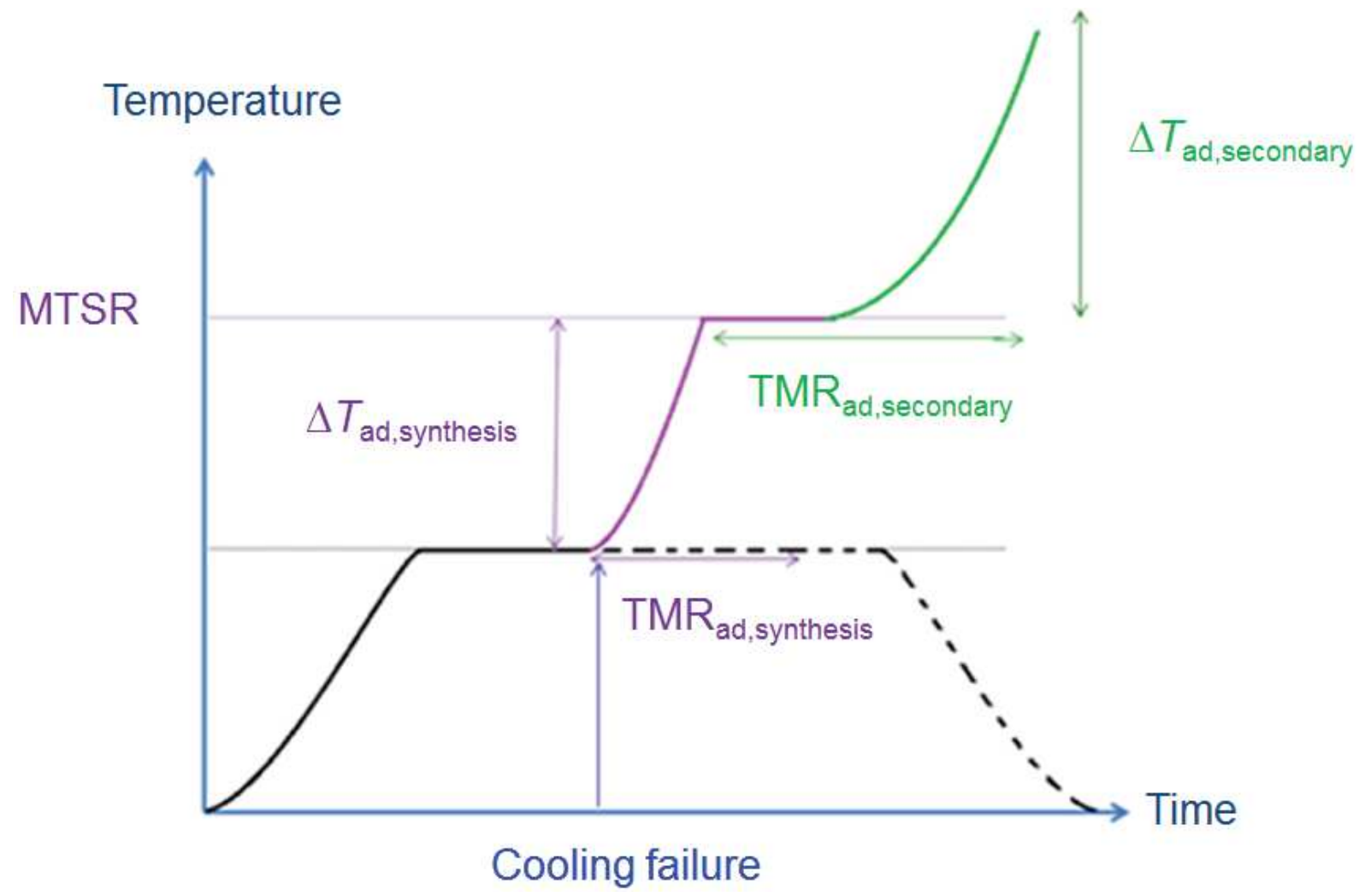

Fig. 2 Cooling failure scenario accident 


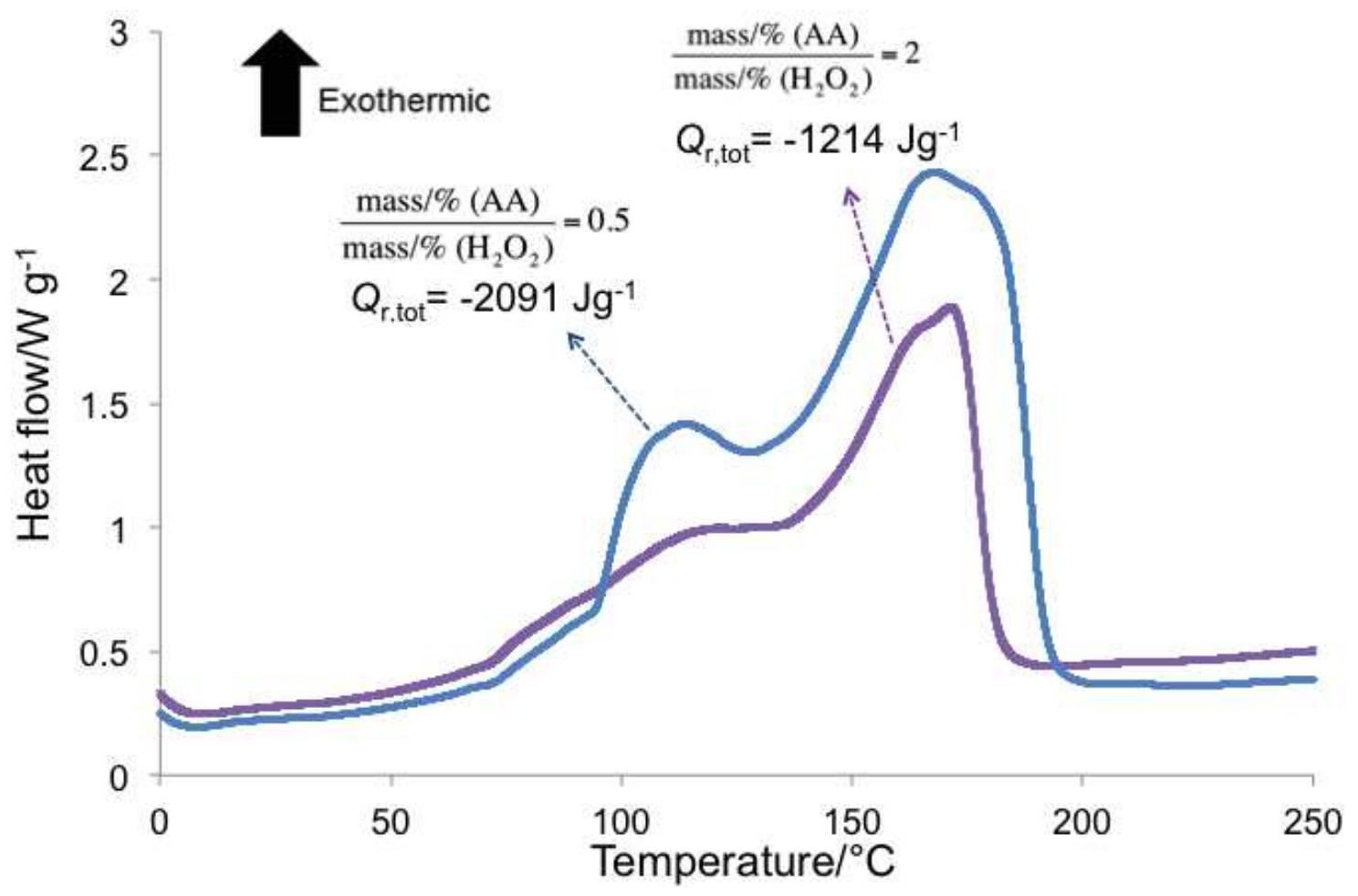

Fig. $3 \mathrm{DSC}$ experiment at $4^{\circ} \mathrm{C} / \mathrm{min}$ at different ratio of acetic acid on hydrogen peroxide 


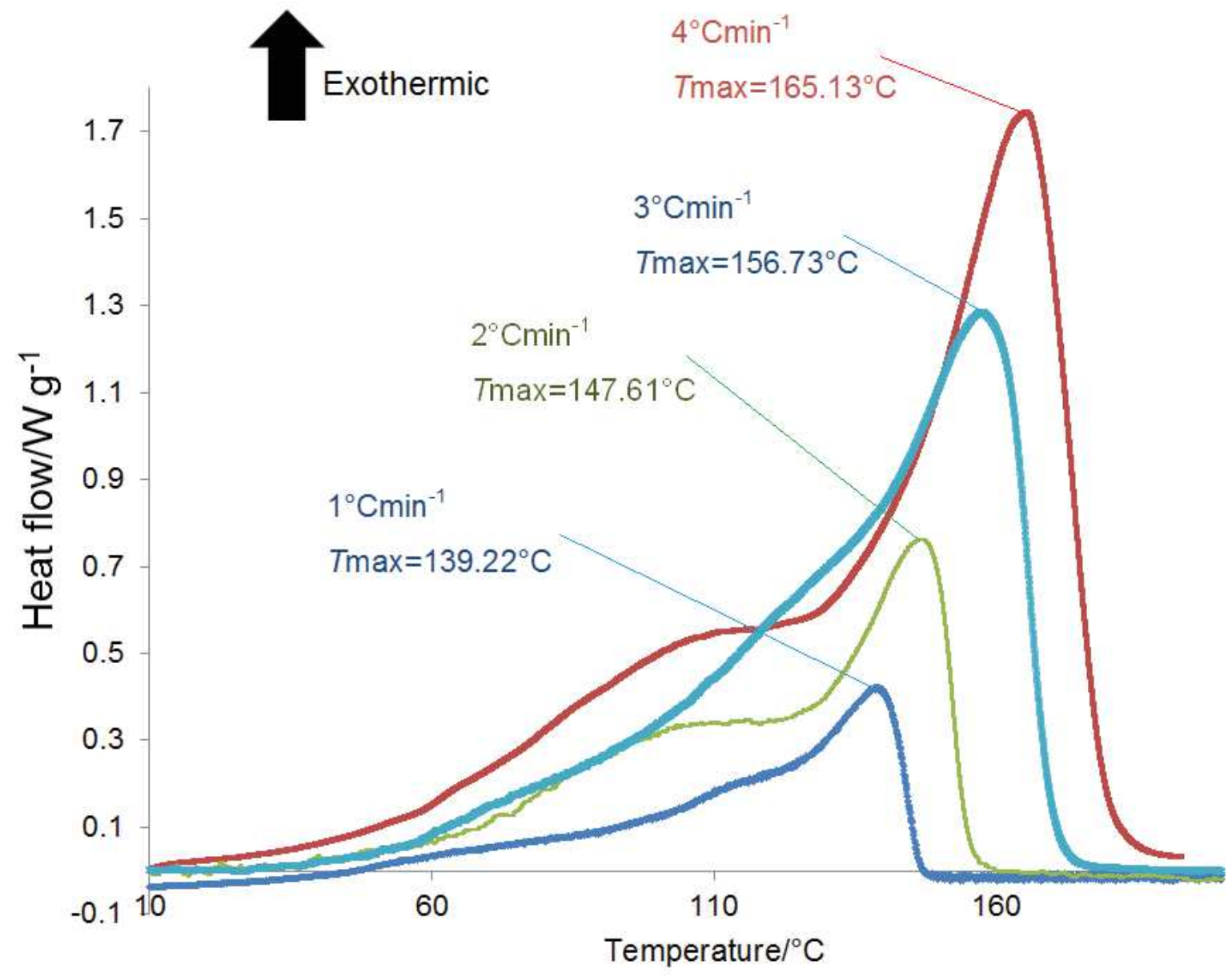

Fig. 4 DSC under dynamic mode 


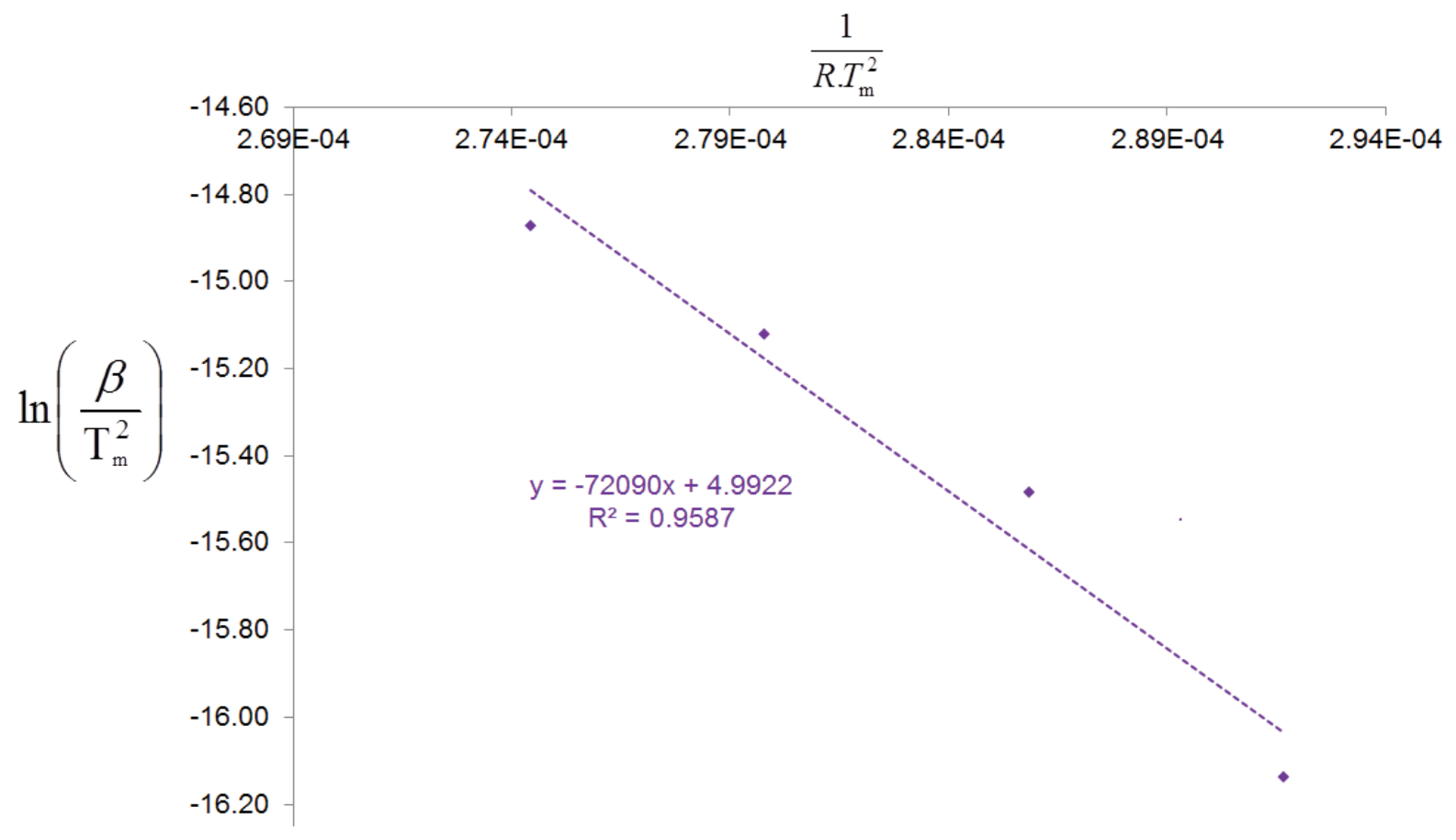

Fig. 5 Kissinger plot for oleic acid epoxidation by peroxyacetic acid 


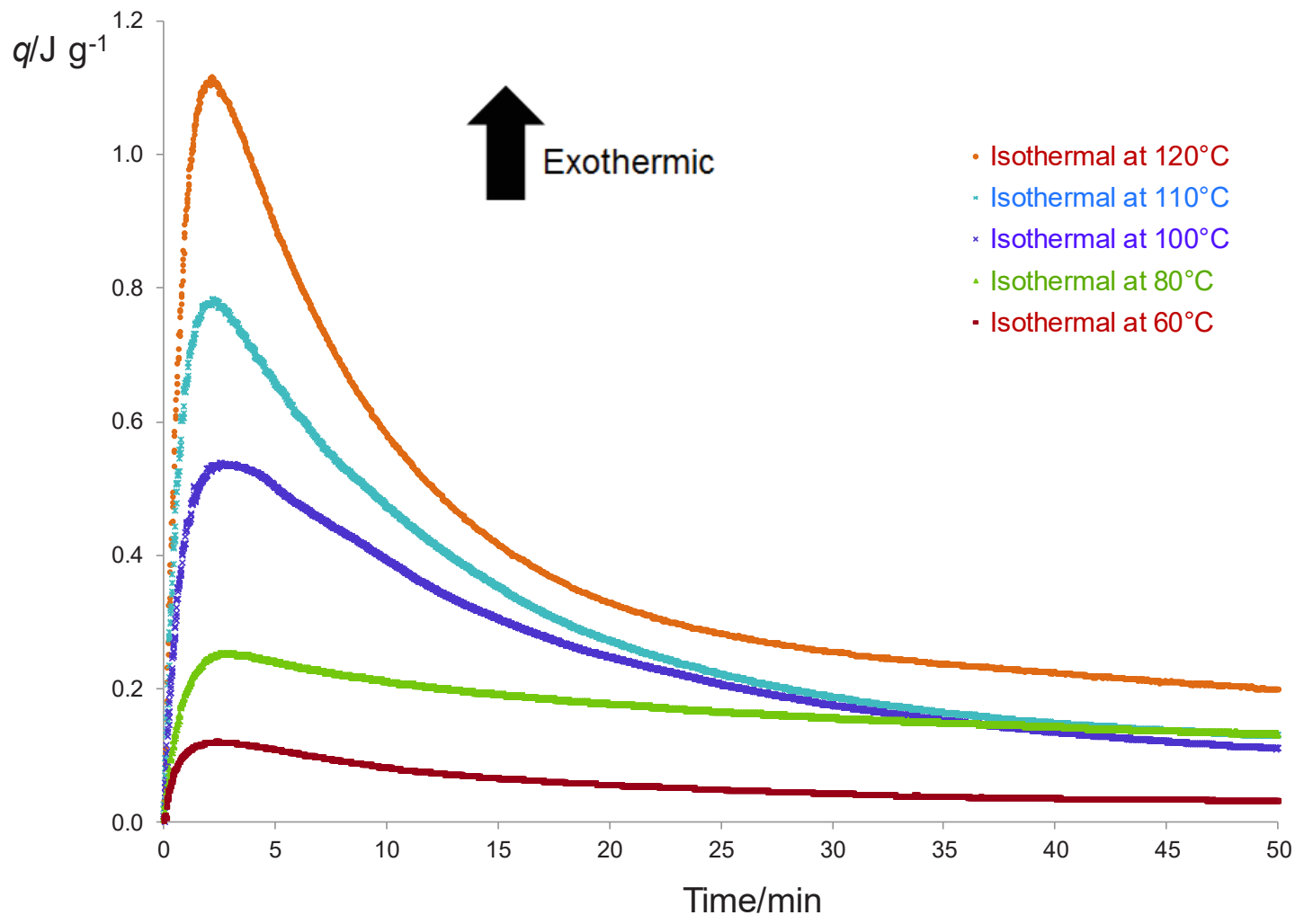

Fig. 6a DSC under isothermal condition for the epoxidation of oleic acid by peroxyacetic acid within temperature range of $60-120^{\circ} \mathrm{C}$ 


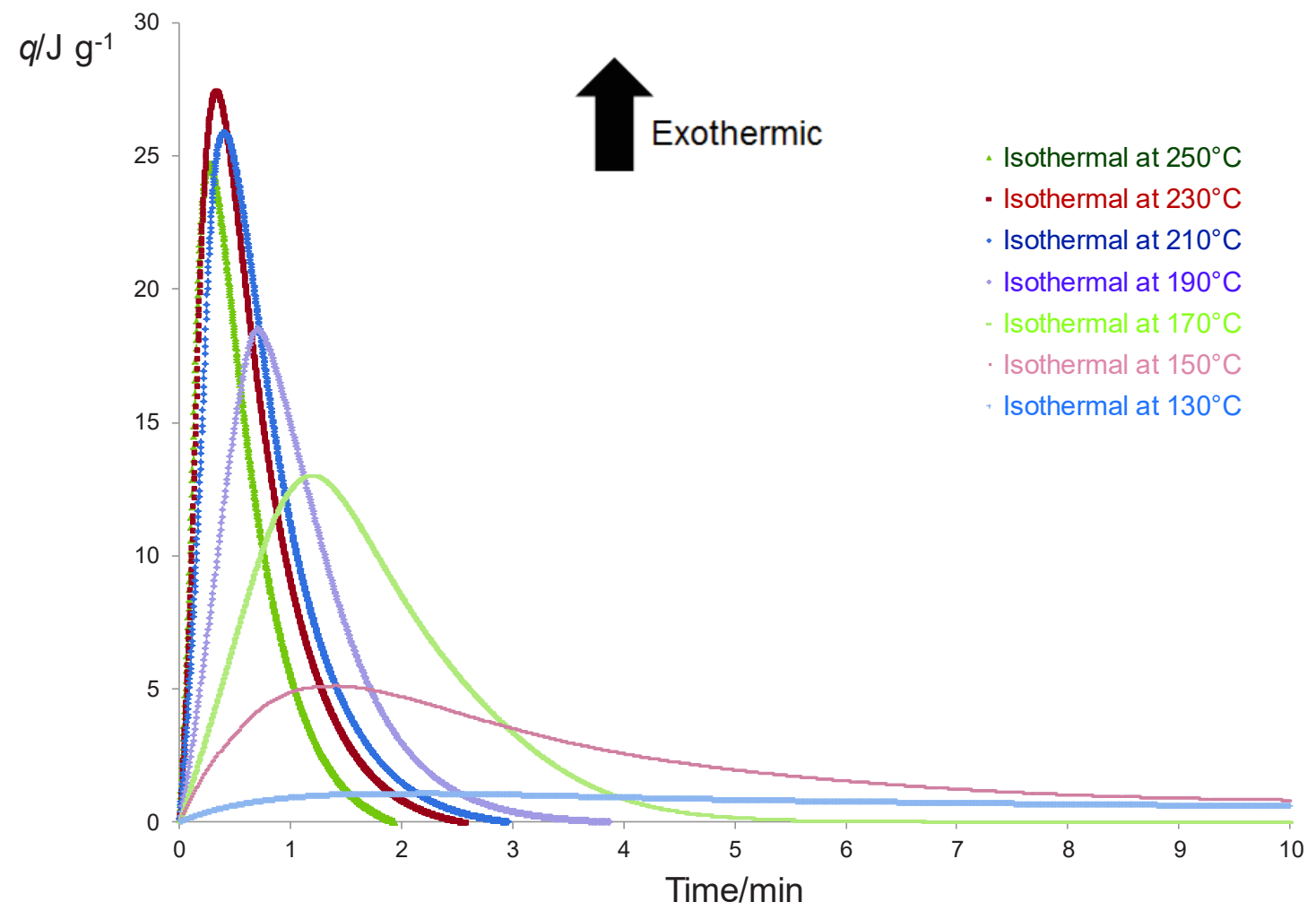

Fig. 6b DSC under isothermal condition for the epoxidation of oleic acid by peroxyacetic acid within temperature range of $130-250^{\circ} \mathrm{C}$ 


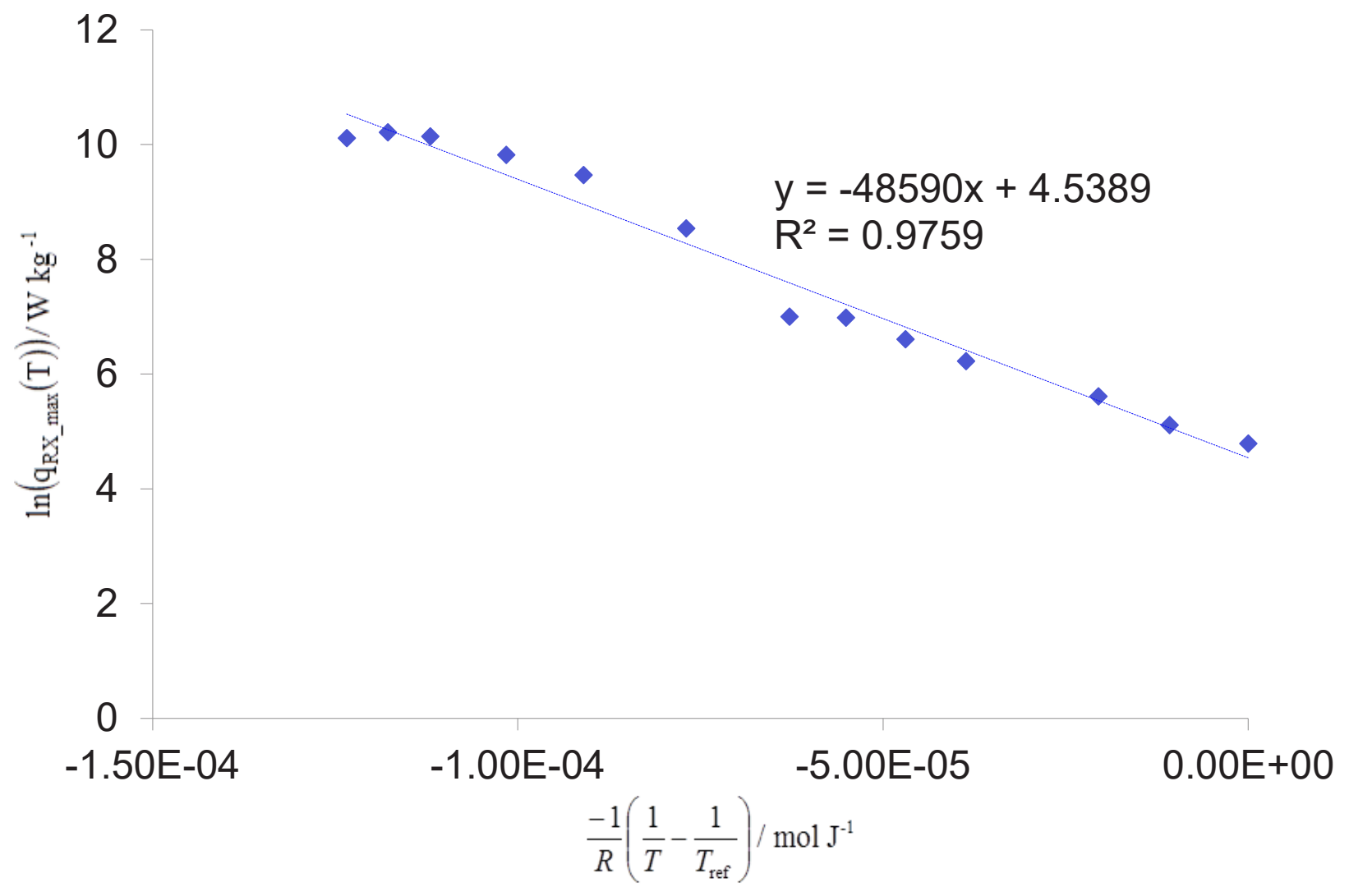

Fig. 7 Evolution of $\ln \left(\mathrm{q}_{\mathrm{RX} \_ \text {max }}\right)$ versus $\frac{-1}{\mathrm{R}}\left(\frac{1}{\mathrm{~T}}-\frac{1}{\mathrm{~T}_{\text {ref }}}\right)$ 


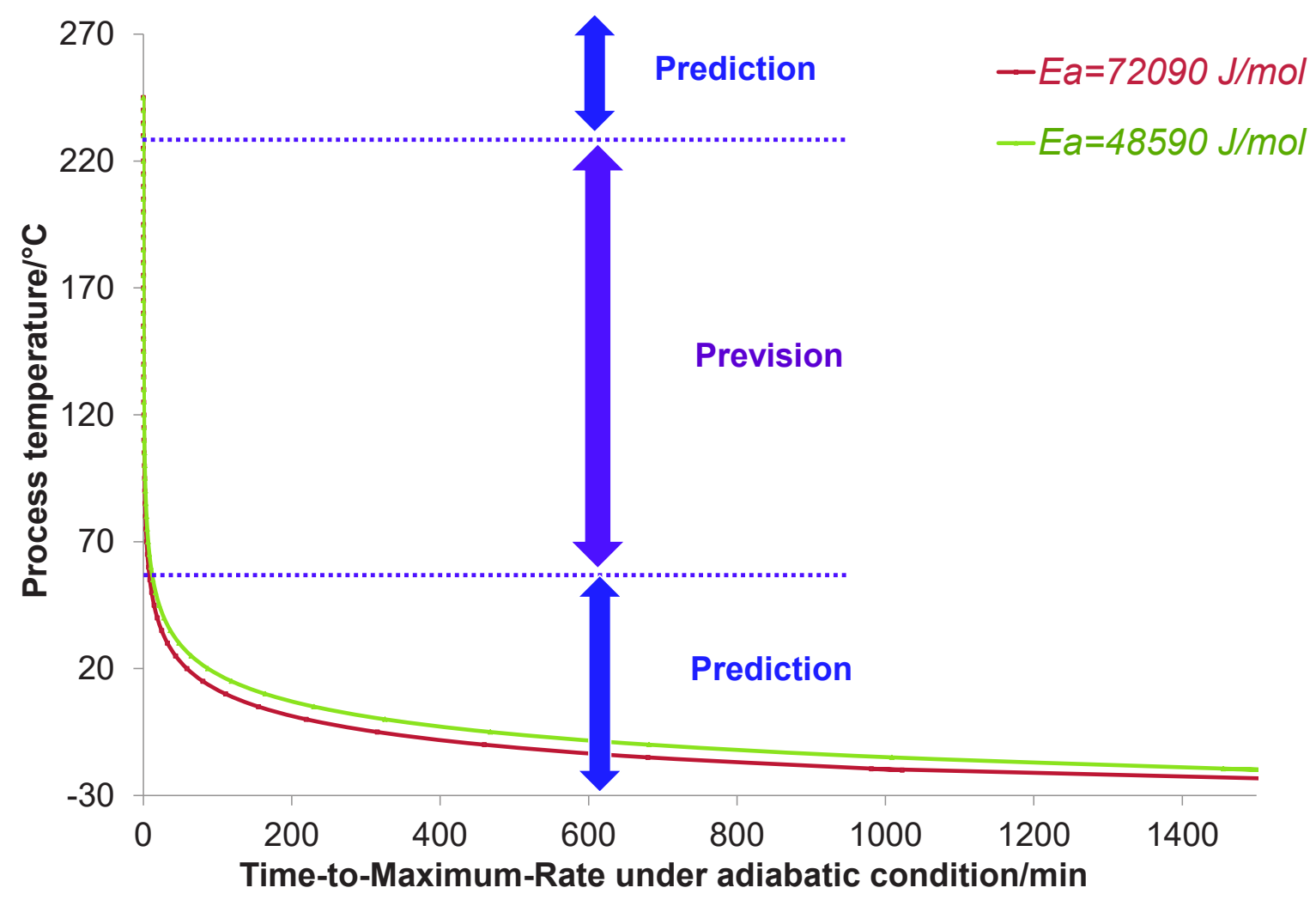

Fig. $8 T_{M R}$ from DSC data 


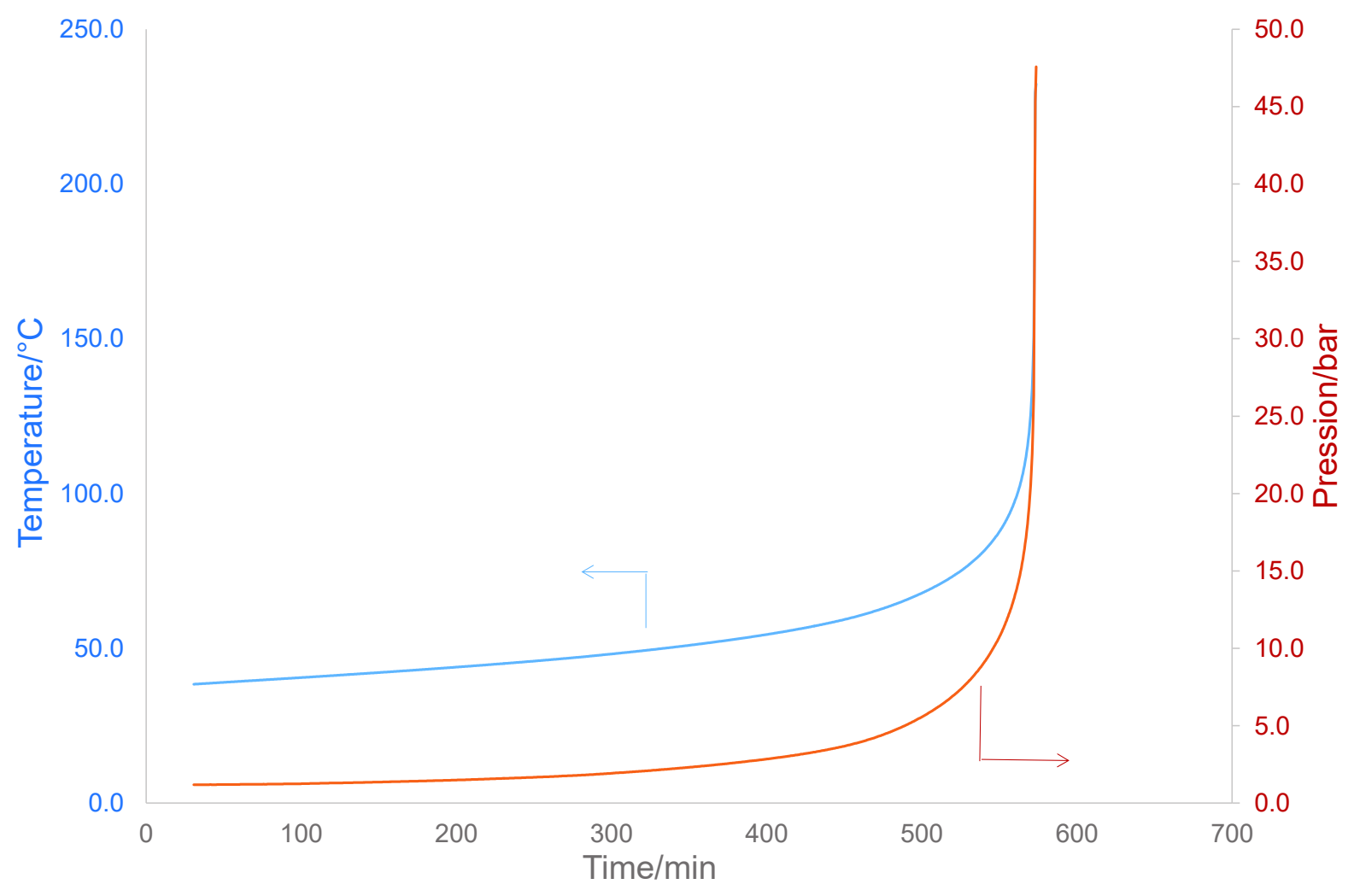

Fig. 9 Evolution of temperature and pressure in the ARC 


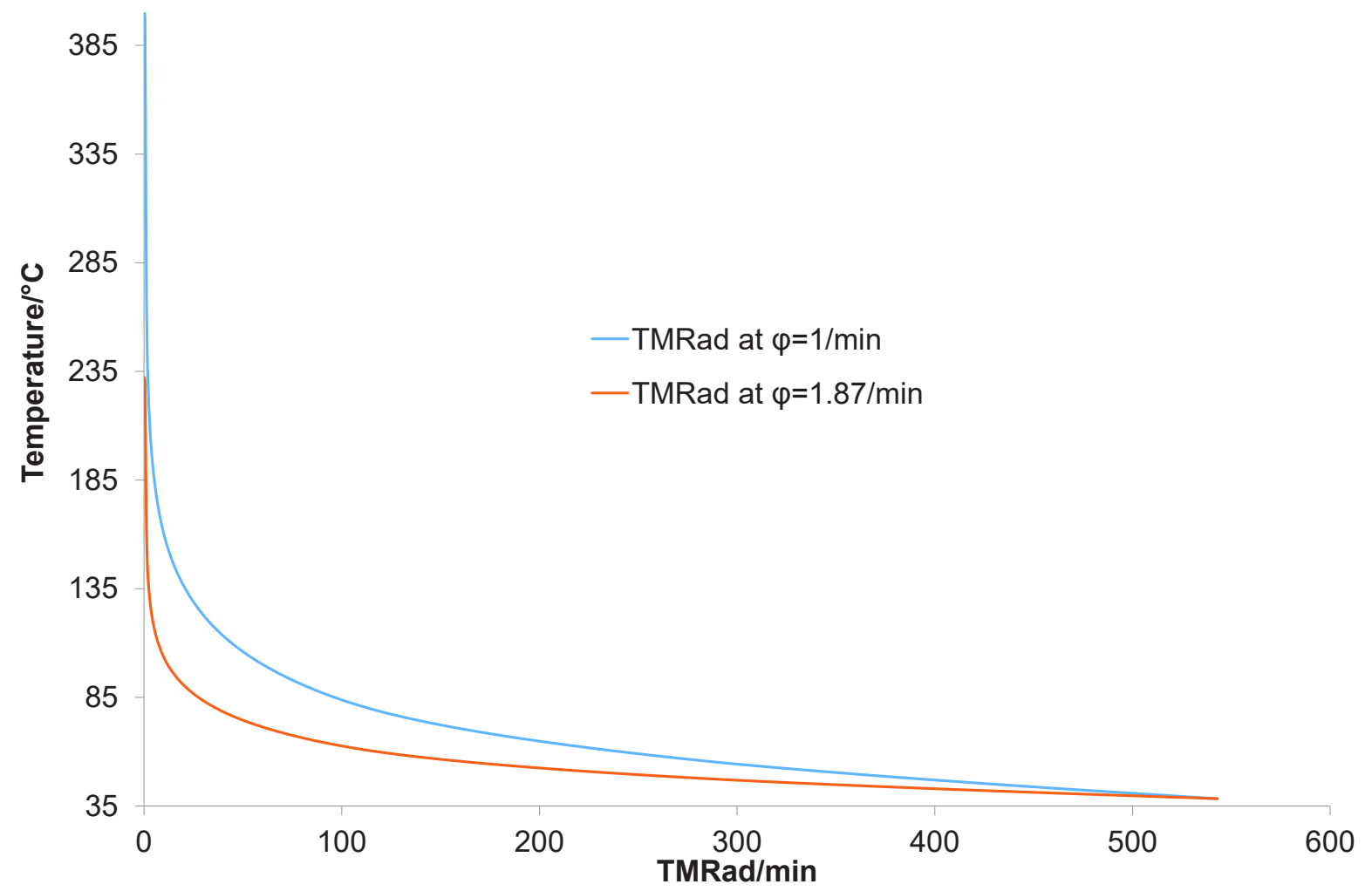

Fig. 10 Evolution of $\mathrm{TMR}_{\mathrm{ad}}$ with $\varphi$-factor 


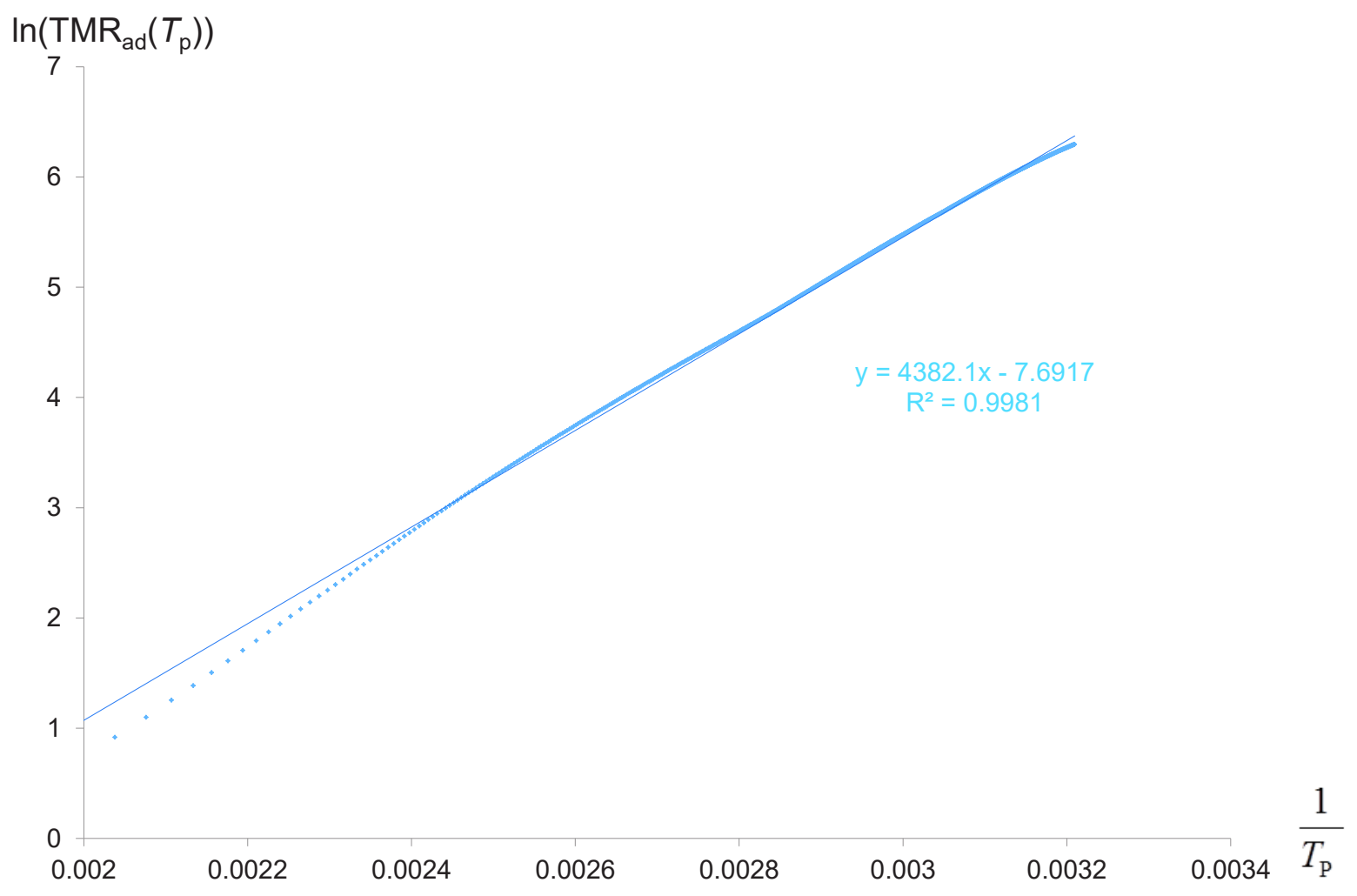

Fig.11 $\ln \left(\mathrm{TMR}_{\mathrm{ad}}\right)$ versus $T_{\mathrm{P}}^{-1} / \mathrm{K}^{-1}$ 


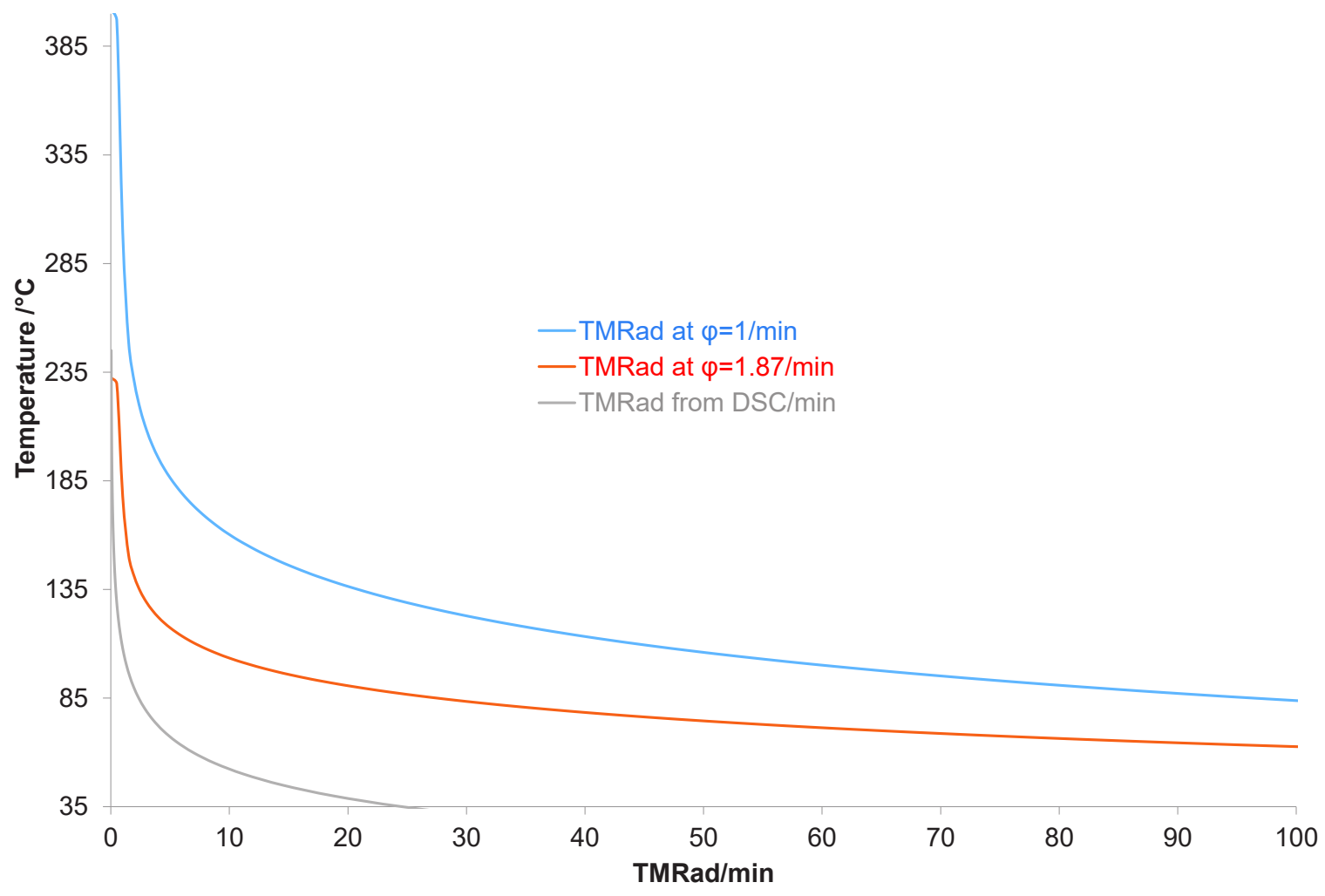

Fig. 12 Evolution of $\mathrm{TMR}_{\mathrm{ad}}$ at different process temperatures 
Table 1 Experimental matrix

\begin{tabular}{|ccc|}
\hline Acetic acid & $0-30$ & mass $/ \%$ \\
$\mathrm{H}_{2} \mathrm{O}_{2}$ & $14-20$ & mass $/ \%$ \\
$\mathrm{H}_{2} \mathrm{O}$ & $28-55$ & mass $/ \%$ \\
Oleic acid & $31-34$ & mass $/ \%$ \\
\hline Sample mass & $5-8$ & $\mathrm{mg}$ \\
\hline Temperature ramp & $0-5$ & ${ }^{\circ} \mathrm{Cmin}^{-1}$ \\
\hline Temperature & $60-250$ & ${ }^{\circ} \mathrm{Cmin}^{-1}$ \\
\hline
\end{tabular}


Table 2 Experimental conditions for DSC under dynamic mode

\begin{tabular}{|cccc|}
\hline & Case 1 & Case 2 & \\
Acetic acid & 30.04 & 10.51 & mass $/ \%$ \\
$\mathrm{H}_{2} \mathrm{O}_{2}$ & 14.86 & 19.30 & mass $/ \%$ \\
$\mathrm{H}_{2} \mathrm{O}$ & 32.82 & 42.04 & $\mathrm{mass} / \%$ \\
Oleic acid & 22.28 & 28.15 & $\mathrm{mass} / \%$ \\
\hline Sample mass & 5.57 & 5.33 & $\mathrm{mg}$ \\
\hline Temperature ramp & 4 & 4 & ${ }^{\circ} \mathrm{Cmin}^{-1}$ \\
\hline
\end{tabular}


Table 3 Safety criteria from DSC results

\begin{tabular}{|c|c|c|}
\cline { 2 - 3 } \multicolumn{1}{c|}{} & $E \mathrm{a}=72090 \mathrm{Jmol}^{-1}$ & $E \mathrm{a}=48590 \mathrm{Jmol}^{-1}$ \\
\hline$T_{\text {final }}{ }^{\circ} \mathrm{C}$ & 544.00 & 544.00 \\
\hline $\mathrm{MTT} /{ }^{\circ} \mathrm{C}$ & 100.00 & 100.00 \\
\hline$T_{\mathrm{p}} /{ }^{\circ} \mathrm{C}$ & 70.00 & 70.00 \\
\hline$T_{\mathrm{D} 24} /{ }^{\circ} \mathrm{C}$ & -24.00 & -19.50 \\
\hline
\end{tabular}


Table 4 Comparison between DSC and ARC

\begin{tabular}{|c|c|c|}
\cline { 2 - 3 } \multicolumn{1}{c|}{} & $\mathrm{DSC}$ & $\mathrm{ARC}$ \\
\hline$T_{\text {final }} /{ }^{\circ} \mathrm{C}$ & 544.00 & 401.94 \\
\hline $\mathrm{MTT} /{ }^{\circ} \mathrm{C}$ & 100 & 100 \\
\hline $\mathrm{MTSR} /{ }^{\circ} \mathrm{C}$ & $\mathrm{x}$ & $\mathrm{x}$ \\
\hline$T_{\mathrm{p}} /{ }^{\circ} \mathrm{C}$ & 70 & 70 \\
\hline$T_{\mathrm{D} 24} /{ }^{\circ} \mathrm{C}$ & -24 & 19.7 \\
\hline$\Delta T_{\text {ad, total }} /{ }^{\circ} \mathrm{C}$ & 474 & 331.94 \\
\hline $\mathrm{TMR}_{\text {ad,total }}\left(70{ }^{\circ} \mathrm{C}\right) / \mathrm{min}$ & 4.41 & 164 \\
\hline
\end{tabular}

